\title{
BADANIE ŚLADU AERODYNAMICZNEGO MODELU OBLODZONEGO CIEGNA MOSTU PODWIESZONEGO
}

\begin{abstract}
W niniejszym artykule przedstawiono sposób i wyniki badania płaskiego przepływu powietrza w śladzie aerodynamicznym za nieruchomym modelem oblodzonego cięgna mostu podwieszonego w zakresie liczby Reynoldsa od 2,7 $10^{4}$ do $6,4 \cdot 10^{4}$, przy średniej intensywności turbulencji 3\%.Badania wykonano w tunelu aerodynamicznym z komorą klimatyczną Laboratorium Czeskiej Akademii Nauk w Telč. W komorze klimatycznej przeprowadzono doświadczalne oblodzenie modelu cięgna mostowego o osi nachylonej pod kątem $30^{\circ}$ do płaszczyzny poziomej. Kształt oblodzonej powierzchni cięgna zarejestrowano metodą fotogrametrii cyfrowej. Do badań w komorze aerodynamicznej wykonano nowy model oblodzonego cięgna metodą druku 3D.Badanie śladu aerodynamicznego wykonano z zastosowaniem optycznej wizualizacji PIV (ang. Particle Image Velocimetry), zwanej cyfrową anemometrią obrazową. Na podstawie wizualizacji ustalone zostały prędkości i kierunki przepływu poszczególnych strug powietrza, parametry geometryczne ścieżki wirowej i lokalizacja punktów oderwania od modelu warstwy przyściennej powietrza. Otrzymane wyniki pozwoliły na poznanie zjawisk zachodzących podczas opływu powietrza wokół modelu oblodzonego cięgna.
\end{abstract}

Słowa kluczowe: aerodynamika, oblodzenie, cięgno mostowe, optyczna wizualizacja, ścieżka wirowa

\section{Wprowadzenie}

W wyniku opływu powietrza wokół ciał nieopływowych na ścianie nawietrznej ciała powstaje nadciśnienie, zaś za ciałem powstaje obszar obniżonego ciśnienia, nazywany śladem aerodynamicznym. Wypadkowa sił aerodynamicznych działających na ciało w kierunku wiatru nazywana jest siłą oporu aerodynamicznego. Charakter śladu aerodynamicznego, jego cechy geometryczne i lokalizacja punktów oderwania warstwy przyściennej mają decydujący wpływ

\footnotetext{
${ }^{1}$ Autor do korespondencji/ corresponding author: Piotr Górski, Politechnika Opolska, Wydział Budownictwa i Architektury, ul. Katowicka 48, 45-061 Opole, tel.: +48 77 4498588, p.gorski@ po.opole.pl

${ }^{2}$ Marcin Tatara, Politechnika Opolska, Wydział Budownictwa i Architektury, ul. Katowicka 48, 45-061 Opole, tel.: +48 77 4498592, m.tatara@ po.opole.pl
} 
na oddziaływanie napływającego powietrza na ciało. Dlatego poznanie zjawisk zachodzących podczas opływu powietrza wokół budowli, a także poznanie jej ważnych parametrów aerodynamicznych, np. liczby Strouhala i współczynników sił aerodynamicznych, stanowi podstawę do sformułowania matematycznego opisu obciążenia wiatrem $\mathrm{w}$ celu przewidywania odpowiedzi budowli na działanie wiatru. W przypadku ciał o przekrojach kołowych, do których zaliczają się cięgna mostów podwieszonych, zagadnienia te są dobrze poznane i przedstawione w literaturze [2]. Zjawiska opływu powietrza zależą tu przede wszystkim od liczby Reynoldsa, przy czym wyróżnia się jej trzy podstawowe zakresy, tj. podkrytyczny, krytyczny i nadkrytyczny [2].

Oblodzenie cięgien mostów podwieszonych zmienia znacząco opływ powietrza wokół tych elementów, ich aerodynamikę, i może przyczynić się do większego obciążenia cięgien pod wpływem działania wiatru. Potwierdzeniem tego są wyniki pomiaru drgań wymuszonych wiatrem oblodzonego pionowego wieszaka mostu wiszącego Great Belt East Bridge w Danii [3]. Drgania wieszaka, które zarejestrowano w dniu 29.03.2001r., charakteryzowały się amplitudą rzędu 1,4 m w kierunku poprzecznym do kierunku wiatru i $1,0 \mathrm{~m} \mathrm{w}$ kierunku wiatru. Należy podkreślić, że tak duże amplitudy drgań pod wpływem wiatru nie były obserwowane $\mathrm{w}$ przypadku nieoblodzonego wieszaka. Wyjaśnienie przyczyn obciążenia oblodzonych cięgien mostowych pod wpływem działania wiatru wymaga poznania zjawisk zachodzących podczas opływu powietrza wokół tych elementów i ich parametrów aerodynamicznych. Publikacje dotyczące tych zagadnień są dotychczas nieliczne i niewystarczające do pełnego opisu problemu, stąd obecnie istnieje duża potrzeba wykonania takich badań.

$\mathrm{W}$ artykule przedstawiono sposób i wyniki badania płaskiego przepływu powietrza w śladzie aerodynamicznym za nieruchomym modelem oblodzonego

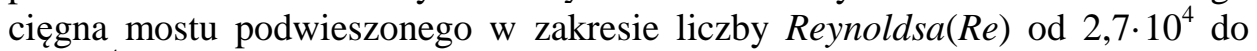
$6,4 \cdot 10^{4}$, przy średniej intensywności turbulencji $3 \%$.Badania wykonano w tunelu aerodynamicznym z komorą klimatyczną Laboratorium Czeskiej Akademii Nauk w Telč. Zastosowano optyczną wizualizację PIV (ang. Particle Image Velocimetry), zwaną cyfrową anemometrią obrazową. Określono prędkości i kierunki przepływu poszczególnych strug powietrza, parametry geometryczne ścieżki wirowej, a także lokalizację punktów oderwania od modelu warstwy przyściennej strug powietrza. Otrzymane wyniki pozwoliły na poznanie zjawisk zachodzących podczas opływu powietrza wokół modelu oblodzonego cięgna.

\section{Doświadczalne oblodzenie i przygotowanie modelu cięgna do badań w komorze aerodynamicznej}

W komorze klimatycznej tunelu aerodynamicznego wykonano doświadczalne oblodzenie modelu cięgna o przekroju kołowym o średnicy zewnętrznej $16 \mathrm{~cm}$ i długości modelu $250 \mathrm{~cm}$. Model zamocowano pod kątem $30^{\circ}$ do płaszczyzny poziomej na przygotowanej konstrukcji ramowej. W wyniku oblodzenia 
otrzymano niesymetryczny przekrój poprzeczny modelu, tj. w górnej części kształt oblodzenia zbliżony był do kołowego, zaś w dolnej części powstało charakterystyczne oblodzenie w postaci żeber. Całkowita wysokość oblodzonego przekroju poprzecznego wyniosła 19,2 cm, zaś jego szerokość $18,1 \mathrm{~cm}$. Kształt oblodzonej powierzchni cięgna zarejestrowano metodą fotogrametrii cyfrowej. Do badań w komorze aerodynamicznej wykonano nowy model oblodzonego cięgna w skali 1:1,6 metodą druku 3D. Wysokość przekroju poprzecznego tego modelu była równa 12,0 cm, szerokość 11,3 cm, zaś długość 43,5 cm (rys. 1).

Dokładny opis sposobu, warunków i końcowego efektu oblodzenia modelu cięgna, a także sposobu przygotowania nowego modelu oblodzonego cięgna do badań w komorze aerodynamicznej przedstawiono w pracy [4].

a)

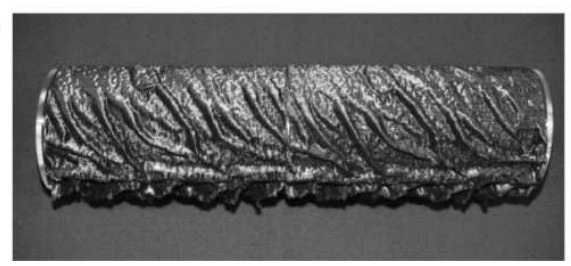

b)

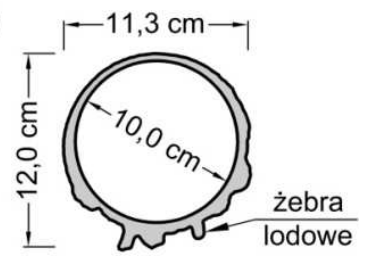

Rys. 1. a) Model oblodzonego cięgna i b) przekrój poprzeczny modelu Fig. 1. a) Iced cable model andb) the cross-section of the model

\section{Sposób i warunki wykonania optycznej wizualizacji PIV}

Optyczna wizualizacja PIV polega na cyfrowej rejestracji obrazu płaskiego obszaru zawierającego cząsteczki posiewu poruszające się w przepływie powietrza i charakteryzujące ten przepływ. Rejestrowana powierzchnia przepływu oświetlana jest płaszczyzną światła lasera, tzw. nożem świetlnym, zaś rejestracja tej powierzchni odbywa się w kierunku prostopadłym do kierunku światła. W celu wyznaczenia pola prędkości i kierunków poszczególnych strug powietrza konieczna jest rejestracja obrazów w odpowiednio krótkich i znanych odstępach czasowych, np. co 0,1 sekundy. Następnie na podstawie dwuwymiarowej funkcji korelacji wzajemnej zarejestrowanych obrazów wyznaczane jest pole przemieszczeń cząsteczek posiewu. Znając czas pomiędzy zdjęciami można wyznaczyć pole prędkości przepływu [1].

Do wykonania wizualizacji PIV wykorzystano następujące elementy:(1)laser impulsowy, emitujący światło w kolorze zielonym, o podwójnej głowicy harmonicznej $532 \mathrm{~nm}$ i częstości 47-63 Hz, w którym optyka noża świetlnego zamocowana była bezpośrednio do głowicy lasera, (2) szybkoklatkową kamerę cyfrową $(C C D)$ wyposażoną w stałoogniskowy obiektyw Zeiss Planar T o ogniskowej $50 \mathrm{~mm}$ i maksymalnej przesłonie f/1,4, (3) generator posiewu połączony z zewnętrznym źródłem powietrza pod ciśnieniem, (4) moduł synchronizacji lasera i kamery, (5) specjalistyczne oprogramowanie DynamicStudio do sterowania urządzeniami pomiarowymi i umożliwiające analizę i obróbkę otrzymanych wyników. 
Wizualizację śladu aerodynamicznego za modelem oblodzonego cięgna wykonano w przestrzeni pomiarowej komory aerodynamicznej tunelu o szerokości $1,9 \mathrm{~m}$, wysokości $1,8 \mathrm{~m}$ i długości $11,0 \mathrm{~m}$. W czasie badań nie modelowano warstwy przyziemnej przepływu powietrza, tj. na podłodze przestrzeni pomiarowej nie ustawiono żadnych przeszkód. Intensywność turbulencji powietrza, mierzona przed modelem, wyniosła około $3 \%$, średnia temperatura powietrza $25,6^{\circ} \mathrm{C}$, zaś ciśnienie atmosferyczne $962 \mathrm{hPa}$. Model sekcyjny oblodzonego cięgna zamocowano nieruchomo w pozycji poziomej, poprzecznie do kierunku napływającego powietrza, do specjalnie przygotowanej ramy(rys. 2a). Jeden bok ramy został zabudowany sztywną osłoną w kolorze czarnym, która stanowiła tło rejestrowanego obrazu w czasie wykonywania wizualizacji PIV. Model umieszczono na wysokości $66 \mathrm{~cm}$, licząc od płaszczyzny podłogi przestrzeni pomiarowej do osi modelu, żebrami oblodzenia do dołu, tj. zgodnie $\mathrm{z}$ układem oblodzenia otrzymanym w komorze klimatycznej.

Generator posiewu umieszczono wewnątrz przestrzeni pomiarowej tunelu i połączono z zewnętrznym źródłem powietrza pod ciśnieniem. Umożliwił on wytworzenie mgły olejowych cząstek znacznikowych (Di-Ethyl-Hexyl-Sebacate). W czasie badania cząstki posiewu dostarczone do przestrzeni pomiarowej tunelu krążyły w jej zamkniętym obiegu. Źródło impulsowego światła lasera, umieszczone w górnej części komory aerodynamicznej i połączone z systemem sterowania, emitowało światło w płaszczyźnie pionowej. Kamera CCD rejestrująca obrazy cząsteczek posiewu, poruszające się w śladzie aerodynamicznym badanego modelu była zsynchronizowana $\mathrm{z}$ laserem. Wymiary rejestrowanej powierzchni przepływu wyniosły 520 x $520 \mathrm{~mm}$ (rys. 2b).W celach porównawczych wykonano wizualizację śladu aerodynamicznego za gładkim walcem kołowym o średnicy zewnętrznej równej $10,0 \mathrm{~cm}$, przy średniej prędkości wiatru przed modelem $\bar{u}=3,6 \mathrm{~m} / \mathrm{s}\left(R e=2,2 \cdot 10^{4}\right)$. Jest to zakres podkrytyczny liczby Reynoldsa walca kołowego, dla którego wyznaczono długość łuku, określoną kątem $\alpha$, występowania punktu oderwania się strug powietrza. Wyniki przedstawione na rys. 3 (wymiary podano $\mathrm{w}$ milimetrach) są zgodne $\mathrm{z}$ wynikami badań znanymi w literaturze, np. [2], co potwierdza słuszność zastosowanej metodologii badań.

a)

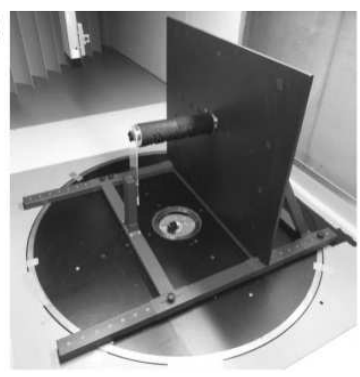

b)

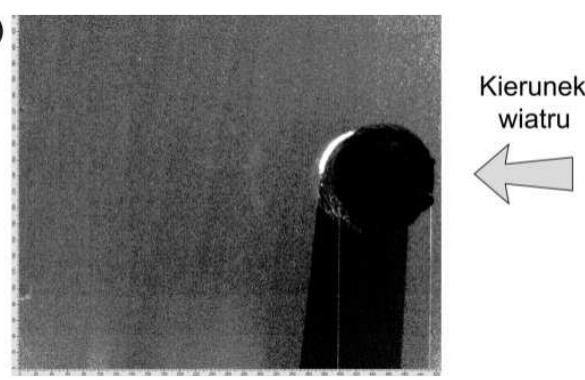

Rys. 2. a) Widok modelu oblodzonego cięgna zamocowanegowspecjalnej ramie, b) obszar wizualizacji PIV z widocznymi cząstkami posiewu w świetle lasera

Fig. 2. a) View of the iced cable model fixed in the special frame, b) area of the PIV visualization with visible seeded particles in laser sheet 
a)

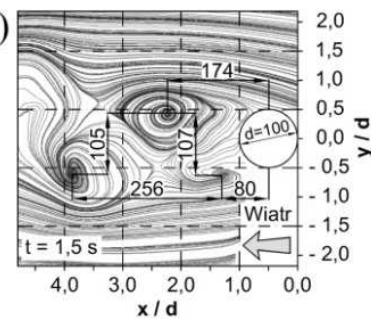

b)

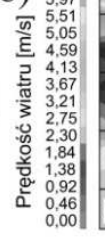

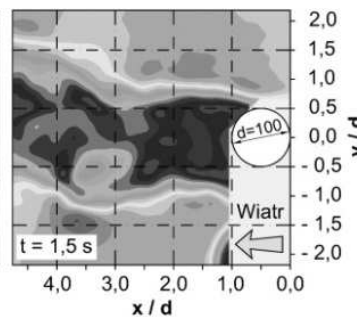

c)

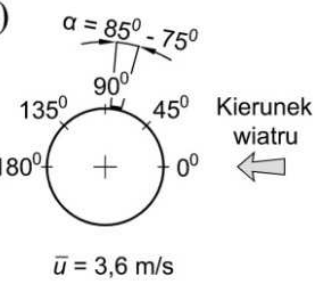

Rys. 3. Dla walca kołowego przy $R e=2,2 \cdot 10^{4}$ : a) linie strug powietrza, b) pole prędkości przepływu powietrzaza modelem i c)lokalizacja punktów oderwania warstwy przyściennej

Fig. 3. For the circular cylinder at $R e=2.2 \cdot 10^{4}$ : a) streamlines, b) velocity field of the airflow behind the model and c) the location of the separation points of flowboundary layer

\section{Wyniki badań}

Optyczną wizualizację PIV śladu aerodynamicznego modelu oblodzonego cięgna wykonano przy średniej prędkości wiatru przed modelem $\bar{u}$ równej $3,6 \mathrm{~m} / \mathrm{s}, 4,9 \mathrm{~m} / \mathrm{s}$ i $8,7 \mathrm{~m} / \mathrm{s}$, której odpowiadała liczbaReynoldsao wartości odpowiednio $2,7 \cdot 10^{4}, 3,6 \cdot 10^{4} \mathrm{i} 6,4 \cdot 10^{4}$. Przy każdej prędkości wiatru rejestrowano obraz przepływu w czasie 5 sekund w odstępach co 0,1 sekundy. Materiał, z którego wykonano model badawczy(plastik kukurydziany typu PLA) jest materiałem nieprzeźroczystym, stąd w czasie badania nie było możliwe oświetlenie światłem lasera obszaru pod modelem badawczym. W celu wyznaczenia lokalizacji punktów oderwania warstwy przyściennej od spodniej strony modelu (po stronie żeber lodowych) dodatkowo wykonano wizualizację przepływu za modelem $\mathrm{w}$ położeniu modelu żebrami oblodzenia dogóry. Otrzymane wyniki przedstawiono na rys. 4-6 (wymiary podano $\mathrm{w}$ milimetrach).

\section{Podsumowanie i wnioski}

Na podstawie wykonanychbadań sformułowano następujące wnioski:

a) badanie śladu aerodynamicznego modelu oblodzonego cięgna mostu podwieszonego wykonano za pomocą optycznej wizualizacji PIV płaskiego przepływu powietrza za nieruchomym modelem. Określono prędkości i kierunki przepływu poszczególnych strug powietrza, strukturę i parametry geometryczne ścieżki wirowej, a także lokalizację punktów oderwania od modelu warstwy przyściennej strug powietrza,

b) stwierdzono, że dla $R e=2,7 \cdot 10^{4}$ i $R e=3,6 \cdot 10^{4}$ (rys. 4 i 5) struktura śladu aerodynamicznego za oblodzonym cięgnem ma cechy zbliżone do opływu podkrytycznego walca kołowego. Wskazuje na to wirowy i niesymetryczny przepływ powietrza za modelem. Wiry powstają okresowo, na przemian po jednej i po drugiej stronie w szerokim pasie za modelem. Punkt oderwania się strug powietrzawystępuje w punkcie odległym od punktu czołowego modelu, tj. od strony naporu wiatru,na długości łuku odpowiadającej kątomod $64^{0}$ do $96^{0}$, 
a)

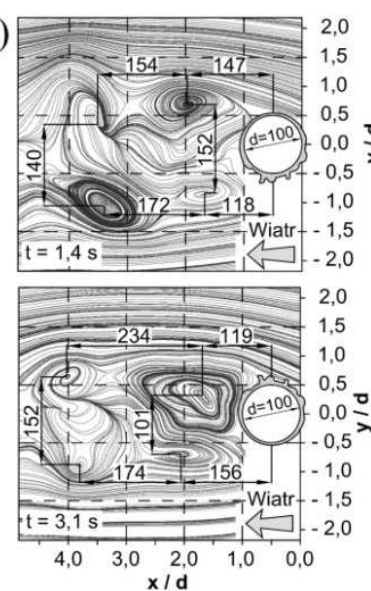

b)

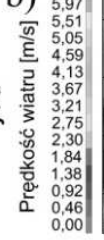

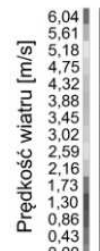
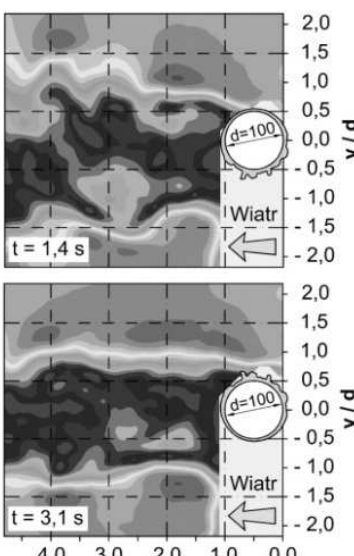

c)
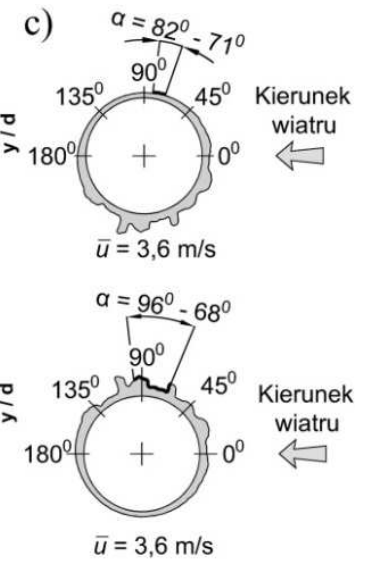

Rys. 4. Dlamodelu oblodzonego cięgna przy $R e=2,7 \cdot 10^{4}$ : a) linie strug powietrza, b) pole prędkości przepływu powietrza za modelem i c) lokalizacja punktów oderwania warstwy przyściennej

Fig. 4. For the circular cylinder at $R e=2.7 \cdot 10^{4}$ : a) streamlines, b) velocity field of the airflow behind the model and c) the location of the separation points of flowboundary layer

a)
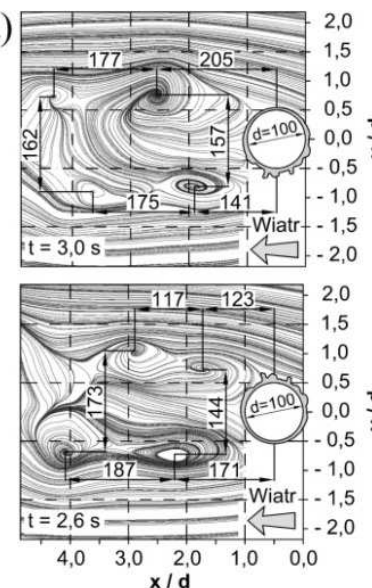

b) 8.00
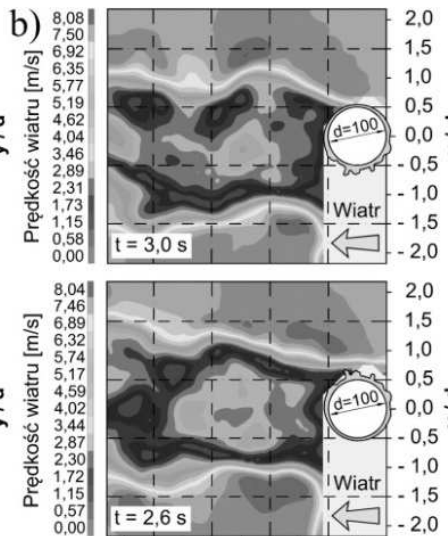

c) $\alpha=85^{\circ}-64^{\circ}$

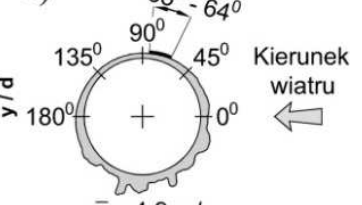

$\bar{u}=4,9 \mathrm{~m} / \mathrm{s}$

$\alpha=95^{\circ}-66^{\circ}$

$90^{\circ}$

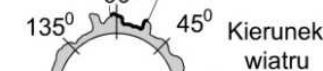

$180^{\circ}(+) 0^{\circ}$

Rys. 5. Dlamodelu oblodzonego cięgna przy $R e=3,6 \cdot 10^{4}:$ a) linie strug powietrza, b) pole prędkości przepływu powietrza za modelem i c) lokalizacja punktów oderwania warstwy przyściennej

Fig. 5. For the circular cylinder at $R e=3 \cdot 6 \cdot 10^{4}$ : a) streamlines, b) velocity field of the airflow behind the model and c) the location of the separation points of flowboundary layer

c) dla $R e=6,4 \cdot 10^{4}$ ślad aerodynamiczny za modelem ma cechy opływu w zakresie krytycznym walca kołowego. Wskazuje na to nieustalony i burzliwy charakter przepływu powietrza za modelem. Punkt oderwania się strug powietrza oscyluje na znacznej długości łuku odpowiadającej kątomod $70^{\circ}$ do $114^{0}$,

d) szerokość śladu aerodynamicznego za oblodzonym cięgnem dla $R e=2,7 \cdot 10^{4}$ i $R e=3,6 \cdot 10^{4}$ jest większa od szerokości śladu dla $R e=6,4 \cdot 10^{4}$.Jest to przyczy- 
a)

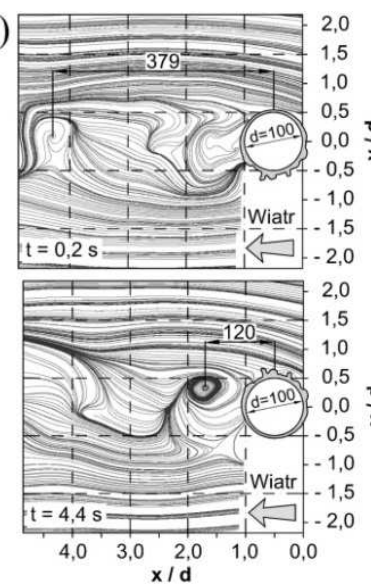

b) ${ }_{13.00}^{1400}$

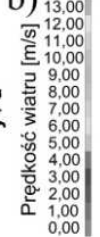

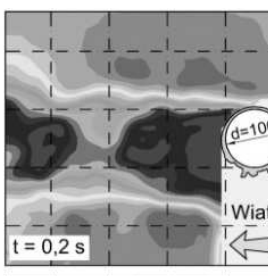
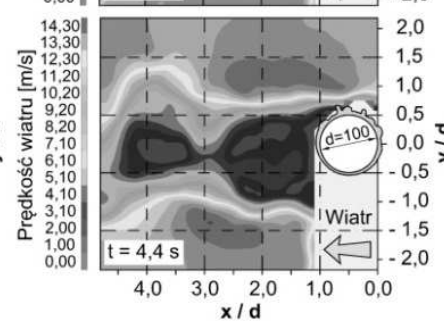

c) $a=112^{\circ}-70^{\circ}$

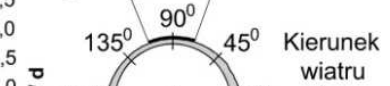

$\frac{\nabla}{>1}$

$180^{\circ}$

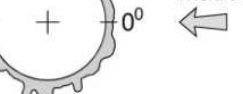

$\bar{u}=8,7 \mathrm{~m} / \mathrm{s}$

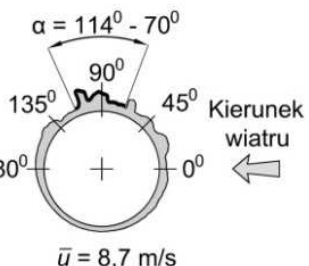

Rys. 6. Dlamodelu oblodzonego cięgna przy $R e=6,4 \cdot 10^{4}$ : a) linie strug powietrza, b) pole prędkości przepływu powietrza za modelem i c) lokalizacja punktów oderwania warstwy przyściennej

Fig. 6. For the circular cylinder at $R e=6.4 \cdot 10^{4}$ : a) streamlines, b) velocity field of the airflow behind the model and c) the location of the separation points of flowboundary layer

ną większej siły oporu aerodynamicznego działającej na badany model. Potwierdziły to wyniki badania współczynnika oporu aerodynamicznego modelu przedstawione w pracy [5].

Spostrzeżenia opisane w punkcie b) i c) potwierdzają wyznaczone zakresy liczby Reynoldsabadanego modelu oblodzonego cięgna na podstawie badania liczby Strouhala, które przedstawiono w pracy [4].

\section{Podziękowania}

Prace badawcze przedstawione $w$ artykule wykonano $w$ ramach zadania badawczego $\mathrm{nr} D \mathrm{DS}-\mathrm{MN} / 30 / \mathrm{WB} / 15$ finansowanego ze środków dotacji celowej przez. MNiSW. Autorzy artykułu dziękujaza wszelka pomoc $w$ realizacji badań pracownikom tunelu aerodynamicznego w sktadzie: prof. Stanislav Pospišili prof. Sergej Kuznetsov.

\section{Literatura}

[1] Cameron S.M.: PIV algorithms for open-channel turbulence research: Accuracy, resolution and limitations,Journal of Hydro-environment Research,vol. 5, 2011,pp. 247-262.

[2] Flaga A.: Inżynieria wiatrowa, Arkady, Warszawa 2008.

[3] Gjelstrup H., Georgakis C., Larsen A.: A preliminary investigation of the hanger vibrations on the Great Belt East Bridge, Proc. of the 7th International Symposium on Cable Dynamics, 10-13 December 2007, Wiedeń, Austria, CD-ROM.

[4] Górski P., Pospišil S., Kuznetsov S., Tatara M., Marušić A.:Strouhal number of bridge cables with ice accretion at low flow turbulence,Wind and Structures, vol. 22, no. 2, 2016, pp. 253-272. 
[5] Górski P., Pospišil S., Kuznetsov S., Tatara M.: Badania modelowe współczynnika oporu aerodynamicznego oblodzonego cięgna mostu podwieszonego, Wydawnictwa Uczelniane Uniwersytetu Technologiczno-Przyrodniczego, Bydgoszcz 2015, s.55-62.

\section{INVESTIGATION OF THE WAKE BEHIND ICED CABLE MODEL OF CABLE-SUPPORTED BRIDGE}

\section{S u m m a r y}

The paper presents the method and results of wind tunnel investigations of two-dimensional airflow in the wake of the stationary iced cable model of cable-supported bridge. The investigations were conducted within the range of the Reynolds number between $2.7 \cdot 10^{4}$ and6.4 $10^{4}$ with the mean turbulence intensity of about $3 \%$. The investigations were performed in the Climatic Wind Tunnel Laboratory of the Czech Academy of Sciences in Telč. The experimental icing of the inclined cable model at an angle of $30^{\circ}$ to the horizontal plane in the climatic chamber of the laboratory was made. The shape of the iced model was registered by a numerical photogrammetry method. For the aerodynamic tunnel investigations the new iced cable model was made by using 3D printing method. The investigations of the wake behind the iced cable model were made using the optical visualization, called Particle Image Velocimetry (PIV). The visualization providedthe information about the velocity and the direction of each separate flow streams, the geometrical features of the vortex street and the location of the separation points of flowboundary layer. The visualization results allowedto recognize the phenomena existing during the airflow around the stationary iced cable model.

Keywords: aerodynamic, icing, bridge cable, optical visualization, vortex street

Przestano do redakcji: 07.06.2016 $r$.

Przyjęto do druku: 30.06 .2016 r.

DOI: $10.7862 / \mathrm{rb} .2016 .49$ 